\title{
The cost and risk impacts of rerouting railroad shipments of hazardous materials
}

\author{
Theodore S. Glickman ${ }^{\mathrm{a}, *}$, Erhan Erkut ${ }^{\mathrm{b}}$, Mark S. Zschocke ${ }^{\mathrm{c}}$ \\ ${ }^{a}$ Decision Sciences Department, School of Business, The George Washington University, Washington, DC, USA \\ ${ }^{\mathrm{b}}$ Faculty of Business, Bilkent University, Ankara, Turkey \\ ${ }^{\mathrm{c}}$ Department of Management Sciences, Faculty of Engineering, University of Waterloo, Waterloo, Ontario, Canada
}

Received 30 September 2005; received in revised form 24 December 2006; accepted 18 January 2007

\begin{abstract}
Rail shipments of hazardous materials expose the population near the routes to the possibility of an accident resulting in a spill. Rail routes are determined by economic concerns such as route length and the revenue generated for the originating carrier. In this paper we consider an alternate routing strategy that takes accident risks into account. We employ a model to quantify rail transport risk and then use a weighted combination of cost and risk and generate alternate routes. In some cases the alternate routes achieve significantly lower risk values than the practical routes at a small incremental cost. While there are generally fewer rerouting alternatives for rail than for road transport, considering the possible consequences of a train derailment we argue that risk should be taken into account when selecting rail routes and that the cost-risk tradeoffs should be evaluated. (C) 2007 Elsevier Ltd. All rights reserved.
\end{abstract}

Keywords: Hazardous materials; Railroad; Transportation; Routing

\section{Introduction}

Hazardous materials ("hazmats") are essential to the societal choices made in industrialized countries. They are used for heating, cooling, farming, medicine, manufacturing, mining, and other industrial processes. Hazmats are often transported in large volumes over long distances. The U.S. Department of Transportation (1998) estimates that over one million hazmat movements occur every day in the USA alone, with a total annual volume estimated to be between 3 and 4 billion tonnes. Most of this volume is moved by truck, with rail shipments accounting for only $10 \%$ of the tonnage moved. However, since most rail shipments are bulk shipments, in case of a release incident the resulting consequences can be very high. According to the U.S. Department of Transportation (2004), in 2002 and 2003 a total of 1685 rail hazmat incidents were reported, with 124 of them classified as serious. Four derailments in this period resulted in evacuations of over a thousand people in each case. Each of these derailments resulted in damages exceeding $\$ 1 \mathrm{M}$ and the total damage due to rail incidents during 2002 and 2003 was

\footnotetext{
* Corresponding author.

E-mail address: glickman@gwu.edu (T.S. Glickman).
}

close to $\$ 10 \mathrm{M}$. Fortunately, there was only one fatality due to a rail hazmat incident in this period.

While the number of deaths and injuries due to all traffic accidents dwarfs the number of deaths and injuries due to hazmat-related accidents, public concern about the risk of hazmat incidents is rather intense. This is primarily due to the involuntary nature of the risk and the potential for significant consequences in case of a rail hazmat incident. For these reasons, the rail transport of hazmat receives considerable public attention.

Reductions in hazmat transport risks can be achieved in different ways. Perhaps the most obvious way in which operations research - along with risk assessment - can make a significant contribution is in analyzing the routing of shipments. Until recently, considerably more attention has been given to the issue of rerouting hazardous materials shipments on highways than to the parallel issue of rerouting hazardous materials shipments by rail. Numerous researchers have studied risk-related hazardous materials routing from a theoretical perspective, including Batta and Chiu (1988), Miller-Hooks and Mahmassani (1998), Erkut and Ingolfsson (2000), and Leonelli et al. (2000). From an applied perspective, highway rerouting has also been studied extensively (Harwood et al., 1993; Glickman and Sontag, 1995; Cassini, 1998), whereas rail rerouting has received less atten- 
tion and been studied primarily as an applied research problem (Glickman, 1983; McNeil, 1991; Moore et al., 1995) or as a policy issue (Glickman, 1990; U.S. Department of Energy, 1998). Compared to these previous studies, the research documented here addresses the cost-benefit tradeoffs of rail rerouting in an applied way, based on a model that is actually used by industry analysts, and recognizing the need to be situation-specific instead of generalizing as to whether rail rerouting is appropriate or inappropriate in every case.

Some might argue that this is not surprising, given that the rail mode generally offers fewer practical alternatives to the routes already being used. Moreover, they might contend that truckload shipments are more conducive to rerouting, given that they are generally independent of one another, while carload shipments headed to various different destinations become highly interdependent once they are placed on the same train. McClure et al. (1988) observed that rail rerouting is different from highway rerouting of hazardous materials for the following reasons:

- The railroad networks are not as dense as highway networks. The total length of U.S. highways is about 15 times greater than the length of the U.S. railroads. This presents a narrower range of routing alternatives for hazardous materials.

- Railroads do not have lines circumventing major population centers comparable to interstate beltways around metropolitan areas.

- A given shipment is likely to be handled by more than one railroad carrier, whereas truck shipments are likely to be limited to a single company. Interchange among railroad companies can introduce inefficiencies in the global route selection process since carriers are motivated to maximize their portion of the movement.

To this list we add these additional reasons:

- Redirecting selected rail shipments might disrupt train schedules.

- If costs increase, some rail traffic might be diverted to the highway mode.

In recent times, however, these concerns may be less compelling because of two significant developments that have led to a new sense of urgency regarding the issue of rail rerouting. One is the threat of domestic terrorist attacks involving tank cars in populated areas and the other is the prospect of numerous spent nuclear fuel shipments on rail cars once the high-level radioactive waste repository opens in Yucca Mountain, Nevada. Due to these concerns, both of which could tip the balance in favor of rerouting certain highly vulnerable or extremely hazardous rail shipments, we need to better understand the associated costs and benefits of rail rerouting as a risk reduction strategy.

The results we present in this paper are intended to shed light on this issue by providing objective estimates of the costrelated and risk-related impacts of diverting trains carrying tank cars of hazardous materials from existing routes to alternative routes that are ostensibly safer (note: spent nuclear fuel will be shipped in specially designed containers that should be less prone to release, in which case the risk estimates provided here would be conservatively high). These impact estimates are produced for a random sample of origin-destination pairs on the U.S. rail system using a network computer model in tandem with a mathematical risk model. For each pair in the sample, we first approximate the "existing route" using the network model's built-in route determination features and then we generate a range of alternative "reduced-risk routes" by incorporating a risk metric into the network model's routing calculations and progressively increasing its influence on route determination by increasing its weight over a range of values.

In reality, the probability of a train accident will generally not depend on whether there are hazmats aboard, although the conditional probability of a release could depend on the number of hazmat cars on the train and the nature of those cars (e.g., with tank cars, some designs are more puncture-resistant than others). Moreover, the severity of the release consequences could depend on the commodity involved, with "toxic inhalation hazard" chemicals generally considered to be among the worst. The risk metric introduced below estimates the size of the expected population that resides within a given radius of the location of a train accident involving a release of hazardous materials, based on average values for the total number of cars in the train, the total number of hazmat cars among those cars, and the conditional probability of release from a hazmat car. Thus it is not commodity dependent. The routing model can be (and has been) used to examine the risks of different commodities. Commodity type can affect the conditional release probability and the impact radius, but for this study we controlled for that by basing every risk on the same representative, generic commodity.

\section{Cost and risk impacts}

The main objective of this analysis is to evaluate the tradeoff between cost and risk when comparing an existing route to a reduced-risk route. As a surrogate for transportation cost we use route length, and we measure risk by estimating the expected population that resides within a given radius of the location of a train accident involving a release of hazardous materials. Our purpose is not to produce the most refined estimates possible, but to provide a reasonable level of insight into the cost-risk tradeoffs involved in rerouting rail shipments of hazardous materials and the advisability of related policy options.

Longer routes require more energy to move the freight and tie up the cars and the freight for longer periods. Since hazmat rail cars usually make up only a fraction of the train, rerouting on longer routes will also affect the arrival time of all the other commodities on the train. Even so, route length alone does not capture all the cost factors associated with rerouting a train. For example, additional costs are incurred if more transfers between carriers become necessary, and car utilization suffers when alternative routes have lower speed limits.

Similarly, our risk metric does not account for every possible risk factor, but it captures a number of important factors involved in estimating the likelihood and adverse consequences of hazmat-related train accidents. Table 1 shows the cause categories of hazardous material incidents for 2003 for var- 
Table 1

Hazardous material incidents for 2003 — cause by mode

\begin{tabular}{lccccc}
\hline Mode & Incidents with evacuations & \multicolumn{2}{l}{ Cause } & & \\
\cline { 3 - 6 } & & Human error & Package failure & Accident/derailment \\
\hline Railway & 21 & 5 & 3 & 13 & Other \\
Air & 82 & 74 & 8 & 0 & 0 \\
Highway & 110 & 76 & 15 & 0 & 0 \\
Water & 0 & 0 & 0 & 31 & 0 \\
Totals & 213 & 155 & 26 & 1 \\
\hline
\end{tabular}

ious transportation modes, compiled by the U.S. Department of Transportation (2004). Only the accident/incident causes are explicitly taken into account in our risk model. We address them by assuming that accident/incident rates are correlated with traffic volume and associating different train accident rates with the different annual traffic volumes from link to link. Otherwise we assume that the causes (human error, package failure, and other) are reflected in the accident rates but are independent of the network link and apply evenly across the network.

Commodity type is another important determinant of risk. While not a factor of interest in this macroscopic study, commodity type would have to be addressed when considering the details of a specific situation involving a particular O-D pair. The study by Brown et al. (2000) shows that most of the toxicby-inhalation $(\mathrm{TIH})$ fatalities occurs in rail transportation, while most of the fatalities for flammable materials and explosives occur in highway incidents. Within the TIH category, the breakdown of casualties by specific chemical is given in Table 2 .

In any policy analysis, the fact that circumstances will differ from situation to situation means that a proposed policy may prove to be very attractive in one set of circumstances but not in another. With rail rerouting in particular, in some circumstances it might be highly advantageous because alternative routes exist which are much safer without being more expensive, while in others, it might be out of the question because there is no alternative route that is safer at any cost. Other situations will involve less clear-cut distinctions and an acceptable tradeoff might then be one in which a shipper or carrier agrees to change the route and incur a modest increase in shipping cost in exchange for less risk, realizing the effect that a major release accident can have not only on public safety but also on profitability, given the related costs of emergency response, clean-up, legal damages, insurance, bad publicity, and so on.

Table 2

Distribution of total TIH fatality and injury risk by chemical

\begin{tabular}{lc}
\hline Chemical & Percent of total \\
\hline Chlorine & 58.5 \\
Ammonia & 26.0 \\
Other & 10.0 \\
Hydrogen fluoride & 3.6 \\
Sulfur dioxide & 1.0 \\
Fuming sulfuric acid & 0.5 \\
Fuming nitric acid & 0.4 \\
Total & 100.0 \\
\hline
\end{tabular}

In terms of the cost and risk impacts that we employ (route length and population exposure), the best conceivable outcome is that an alternative route yields a substantially lower risk than the existing route while incurring no additional mileage or possible even reducing the mileage. In their study of the risk-cost tradeoffs in rerouting highway shipments of hazardous materials, Glickman and Sontag (1995) found that in some instances a significant reduction in risk was attainable for a modest increase in travel distance. This analysis reveals whether similar situations also exist in the rail mode.

\section{The network model}

In actual practice, the routing of rail freight shipments is based on a number of factors, including route mileage, track quality, speed restrictions, track ownership, trackage rights, interchange opportunities, yard locations, and revenue sharing. Train schedules and routes are developed in response to the geographical distribution of demands for rail service, subject to constraints imposed by limitations on equipment, personnel and operating practices, and by the limited capacities of tracks and yards. The result is a complex and dynamic pattern of activity in which freight cars are switched from one train to another and handed off from one carrier to another as they move from their points of origination toward their final destinations.

To simulate individual train movements in this system, ALK Associates of Princeton, N.J. developed a computer model of the U.S. rail network and a shortest-path type algorithm for generating the "practical route" between any given pair of origination and termination stations. The model contains about 200,000 miles of rail line and 60,000 freight stations. The model has been used extensively within government and industry for analytical studies involving route determination under alternative scenarios, dealing with a range of concerns including safety, tariffs, and system restructuring. For practical route generation, the network relies on a proprietary database of segment (link) impedances, interchange (node) impedances, track categories, and associated decision rules. Developed heuristically, these features have been fine-tuned over time to produce routings that correspond to actual operating experience. Confidence in the model is demonstrated by its use in generating mileages in the Carload Waybill Sample published annually by the U.S. Department of Transportation's Surface Transportation Board.

The purpose of this model is not to capture every activity and nuance of railroad operations, including actual traffic volumes, schedules, switches, crossings, track geometry, and 
terrain. Rather it is to approximate the actual routing and distances involved when a shipment moves by train from its origin to its destination - with or without pre-specifying the originating and terminating railroads or the interchange points - and to estimate the associated risk in terms of the census-based population that would be exposed to a release anywhere along the generated route. As discussed below, the model is capable of generating routes based solely on ordinary operating parameters such as distance and track quality ("practical routing"), which it does using heuristic methods to estimate link impedances, or based on a combination of these operating parameters and safety-related parameters such as train accident rates that depend on track quality and population density according to census data ("reduced risk routing").

\section{Practical and alternate routes}

We estimated existing routes for the selected O-D pairs using the practical route features of the network model (as opposed to shortest routes). The length of the practical route is usually very close to the length of the shortest route, but is not always the same.

The estimation of alternate routes with reduced risk required additional link data on train accident history and residential population density. Based on these link attributes and others, we calculated $R_{j}$, the value of the risk metric for each link $j$, and combined it with $P_{j}$, the corresponding practical-route impedance value for link $j$, to obtain $C_{j}$, the mixed impedance value for each link. Denoting by $\lambda$ the weight attached to the risk metric, we calculated the mixed impedance as $C_{j}=\lambda R_{j}+(1-\lambda) P_{j}$, using $\lambda=0.0,0.2,0.4,0.8$, and 1.0. If the alternate routes had been determined using $R_{j}$ as the impedance (which corresponds to using $\lambda=1$ in this weighted sum), the results would in many cases have diverged from the corresponding existing routes to an unrealistic extent.

To generate alternate routes with reduced risk, we use a weighted combination of cost and risk and conduct a parametric analysis over the weights. There are many other conceivable methods. For example, one could minimize the maximum risk by successively removing high-risk links from the network prior to routing (see Erkut and Glickman, 1997) or minimize the variance of the consequences (see Erkut and Ingolfsson, 2000). The goal here is not to advocate one approach over the others, but to demonstrate that in certain circumstances rerouting is a worthy option for rail transport of hazmats.

The mathematical model used to calculate the $R_{j}$ values is a simplified version of the model originally developed by Raj and Glickman (1985) to assess tank car risks on railroad routes. We provide this model in the next section.

\section{Network link risk assessment methodology}

A total of seven link-related risk factors were used to assess the risk along each link $j$ of the network, as described below:

1. Link length $\left(d_{j}\right)$ in miles.
2. Link-related accident rate $\left(r_{j}\right)$ in train accidents per loaded car-mile.

We calculated this as the average of two accident rates: (a) link-specific rate $L_{j}$ and (b) national rate $N_{k} . L_{j}$ is the total number of train accidents on link $j$ over a 3 -year period divided by the volume of loaded freight car-miles on link $j$ in the same period, or $A_{j} / V_{j} . N_{k}$ is the national accident rate in the traffic volume category $k$ to which link $j$ belongs, based on the value of $V_{j}$. If $J(k)$ is used to denote the set of links $j$ with traffic volume in category $k$, then we have

$N_{k}=\frac{\sum_{j \in J(k)} A_{j}}{\sum_{j \in J(k)} V_{j}}$

3. Total number of loaded cars per train $(Y)$, assumed to be 50 .

4. Number of tank cars per train loaded with the hazardous material of concern $(X)$, assumed to be 10 .

5. Conditional release probability, the percentage of tank cars damaged or derailed in train accidents that experience a major release $(p)$, assumed to be $25 \%$.

6. The size of the critical impact area associated with a major release of the hazardous material of concern $(a)$, assumed to be a circle with radius one mile.

7. The residential population density in the critical impact area $\left(\rho_{j}\right)$.

We estimated the $\rho_{j}$ values by overlaying the network on a census area map in a GIS and calculated the population density within a band centered on each link, based on the census counts for the areas involved. This procedure employs two layers of data, one containing the outlines of the nation's census tracts and linked to a database of associated population counts, and another containing the network links, around which boundaries are laid out on either side at varying distances, corresponding to different possible impact radii. Then, for each rectangle centered on each link, the patchwork of census tracts either completely or partially with the rectangle is identified and the associated population values are summed up, where the proportion of a census tract's population that enters into the calculation is based on the percentage of its area that falls within the rectangle.

For the most part, experience shows that the actual impacts of hazmat release accidents (fires, explosions, or toxic vapor clouds) affect only small areas in the vicinity of the track, so that this approach provides an adequate approximation. In fact, the study on evacuation times and radii by Mills et al. (1995) shows that the average radius of the evacuation area is $1.2 \mathrm{~km}$ with a standard deviation of $1.4 \mathrm{~km}$. Given that evacuation radii are set based on conservative estimates, the actual impact area of an average incident is likely to be even smaller than $1 \mathrm{~km}$. In some instances, however, there may be other outcomes, such as an elongated, windswept vapor cloud that extends over a long distance, or the extensive environmental impact of a large volume of toxic substance spilling into a body of water. Such scenarios would warrant more detailed GIS analysis, but are outside the scope of this study and tangential to its objectives. 
In an improved model, the use of the GIS could also be expanded further to find alternative routes that circumvent specific facilities that are most vulnerable to the impacts of accidents, such as hospitals and schools. Similar work was done by Panwhar et al. (2000), who used GIS to find alternative routes for hazardous waste shipments through urban areas that avoided both the general population and specific vulnerable facilities.

We calculated the risk on each link $j$ using a simplified version of the model of Raj and Glickman (1985). However, instead of expressing the risk in the form of a risk profile (i.e., a frequency versus consequence curve) we use the following formula for the expected risk per train on a route:

$R=\sum_{j} f_{j} N_{j}$

Here $f_{j}$ is the expected percentage of trains on link $j$ that experience an accident involving a major release of the hazardous material of concern and $N_{j}$ is the expected consequence of such an accident, as measured by the expected number of residents in the critical area of exposure. The products $f_{j} N_{j}$ are summed over the links of the route in question.

Both $f_{j}$ and $N_{j}$ depend on $X_{\mathrm{R}}$, the number of tank cars of concern that experience a major release are damaged or derailed when a train accident occurs, which is reflected in the following formulas for $f_{j}$ and $N_{j}$ :

$f_{j}=r_{j} d_{j} Y P\left(X_{\mathrm{R}}>0\right) \quad$ and $\quad N_{j}=\rho_{j} a E\left(X_{\mathrm{R}}\right)$

These two formulas require knowledge of the probability distribution $P\left(X_{\mathrm{R}}\right)$. Observing that this probability depends on $X_{\mathrm{D}}$, the number of loaded tank cars of concern that are damaged or derailed, we can write the following:

$$
P\left(X_{\mathrm{R}}\right)=\sum_{X_{\mathrm{D}}} P\left(X_{\mathrm{D}}, X_{\mathrm{R}}\right)=\sum_{X_{\mathrm{D}}} P\left(X_{\mathrm{D}}\right) P\left(X_{\mathrm{R}} \mid X_{\mathrm{D}}\right)
$$

where $P\left(X_{\mathrm{D}}, X_{\mathrm{R}}\right)$ is the joint probability that $X_{\mathrm{D}}$ tank cars are damaged or derailed and $X_{\mathrm{R}}$ of those tank cars experience a release.

For $P\left(X_{\mathrm{D}}\right)$, we assume that the probability distribution is hypergeometric, based on the view that the occurrence of tank car damage or derailment as a case of randomly sampling $X_{\mathrm{D}}$ cars out of $Y$ cars without replacement. The number of samples is $X$. Hence we have

$$
P\left(X_{\mathrm{D}}\right)=\frac{\left[X ! /\left[X_{\mathrm{D}} ! X_{N} !\right]\right]\left[(Y-X) ! /\left[\left(Y_{\mathrm{D}}-X_{\mathrm{D}}\right) !\left(Y_{N}-X_{N}\right) !\right]\right]}{Y ! /\left[Y_{\mathrm{D}} ! Y_{N} !\right]}
$$

In (3) $X_{N}$ is the number of tank cars not damaged or derailed among the $X$ tank cars of concern $\left(=X-X_{\mathrm{D}}\right), Y_{\mathrm{D}}$ the number of loaded cars damaged or derailed, and $Y_{\mathrm{N}}$ is the number of loaded cars not damaged or derailed $\left(=Y-Y_{\mathrm{D}}\right)$.

For $P\left(X_{\mathrm{R}} \mid X_{\mathrm{D}}\right)$, we assume that the probability distribution is binomial, based on viewing the occurrence of multiple tank car releases as a Bernoulli process involving $X_{\mathrm{D}}$ damaged or derailed tank cars, each of which has the same probability of
Table 3

Values of the risk factors

\begin{tabular}{ll}
\hline Risk factor & Value \\
\hline Link length & Varies by link \\
Train accident rate & Varies by link \\
Loaded cars per train & 50 \\
Tank cars of concern per train & 5 \\
Conditional release probability & $25 \%$ \\
Critical impact radius & 1 mile \\
Residential population density & Varies by link \\
\hline
\end{tabular}

release $p$. In this case we have

$P\left(X_{\mathrm{R}} \mid X_{\mathrm{D}}\right)=\frac{X_{\mathrm{D}} !}{X_{\mathrm{R}} !\left(X_{\mathrm{D}}-X_{\mathrm{R}}\right) !} p^{X_{\mathrm{R}}}(1-p)^{\left(X_{\mathrm{D}}-X_{\mathrm{R}}\right)}$

Combining equations (1) and (2) with (3) and (4), we obtain the final expressions for $f_{j}$ and $N_{j}$, the factors used to calculate $R_{j}=f_{j} N_{j}$, the risk estimate for link $j: 0$

$$
\begin{aligned}
f_{j} & =r_{j} d_{j} Y\left[1-P\left(X_{\mathrm{R}}=0\right)\right] \\
& =r_{j} d_{j} Y\left[1-\sum_{X_{\mathrm{D}}} P\left(X_{\mathrm{D}}\right) P\left(X_{\mathrm{R}}=0 \mid X_{\mathrm{D}}\right)\right] \\
& =r_{j} d_{j} Y\left[1-\sum_{X_{\mathrm{D}}} P\left(X_{\mathrm{D}}\right)(1-p)^{X_{\mathrm{D}}}\right]
\end{aligned}
$$

and

$N_{j}=\rho_{j} a \sum_{X_{\mathrm{R}}} X_{\mathrm{R}} P\left(X_{\mathrm{R}}\right)=\rho_{j} a \sum_{X_{\mathrm{R}}} X_{\mathrm{R}} \sum_{X_{\mathrm{D}}} P\left(X_{\mathrm{D}}\right) P\left(X_{\mathrm{R}} \mid X_{\mathrm{D}}\right)$

The risk estimate for each link estimates the expected number of residents exposed to the critical impacts of a hazardous material release arising from a train accident, when one or more tank cars contributes to the total amount released. Table 3 shows the risk factors accounted for in the model and the values of the ones that remain constant from one link to another. While these numbers are fairly typical of the values encountered in practice, the specific numbers do not matter as much as the fact that we used the same ones to generate every alternative route.

To summarize, in order to calculate risk as the expected number of people who live in the area that would be affected if the contents of a tank car full of the hazardous material in question were to be released in a train accident, for each link we multiplied together the accident rate, link length, conditional release probability, impact area, and population density on each segment of the route in question and then summed these products. The accident rate is assumed to depend on traffic volume and the conditional release probability is assumed to depend on the train length and the number of tank cars loaded with the hazardous material of concern. The impact area is assumed to depend on how hazardous the material is and the residential population density within that area is based on census statistics. 
Table 4

Route lengths for the sample city pairs (miles)

\begin{tabular}{|c|c|c|c|c|c|c|c|}
\hline \multicolumn{2}{|l|}{ Route } & \multicolumn{6}{|c|}{ Weight $(\lambda)$ attached to risk } \\
\hline Origin & Destination & $0 \%$ & $20 \%$ & $40 \%$ & $60 \%$ & $80 \%$ & $100 \%$ \\
\hline Jackson (MS) & Wichita (KS) & 795 & 804 & 815 & 815 & 815 & 1223 \\
\hline Wichita (KS) & Charleston (WV) & 1058 & 1060 & 1060 & 1060 & 1060 & 1697 \\
\hline Newark (NJ) & Wichita (KS) & 1639 & 1641 & 1626 & 1626 & 1636 & 1853 \\
\hline Baltimore (MD) & Charleston (WV) & 442 & 442 & 617 & 617 & 805 & 842 \\
\hline Milwaukee (WI) & Boston (MA) & 1113 & 1113 & 1113 & 1113 & 1113 & 1297 \\
\hline Wichita (KS) & Providence (RI) & 1705 & 1709 & 1699 & 1694 & 1694 & 1878 \\
\hline Newark (NJ) & Milwaukee (WI) & 1054 & 1054 & 1056 & 1056 & 1056 & 1281 \\
\hline Newark (NJ) & Denver $(\mathrm{CO})$ & 1980 & 1982 & 1982 & 1982 & 1991 & 2284 \\
\hline Des Moines (IA) & Jacksonville (FL) & 1360 & 1441 & 1441 & 1441 & 1441 & 1451 \\
\hline Charleston (WV) & Portland (ME) & 1085 & 1085 & 1171 & 1171 & 1171 & 1208 \\
\hline Augusta (GA) & Detroit (MI) & 976 & 976 & 1240 & 1240 & 1240 & 1423 \\
\hline Indianapolis (IN) & Milwaukee (WI) & 344 & 344 & 344 & 344 & 344 & 645 \\
\hline Little Rock (AR) & Boston (MA) & 1537 & 1601 & 1624 & 1624 & 1624 & 1815 \\
\hline Baltimore (MD) & Billings (MT) & 2151 & 2151 & 2151 & 2151 & 2214 & 2358 \\
\hline Jacksonville (FL) & St. Louis (MO) & 1016 & 1016 & 1016 & 1016 & 1016 & 1016 \\
\hline Birmingham (AL) & Providence (RI) & 1484 & 1429 & 1519 & 1519 & 1519 & 1744 \\
\hline
\end{tabular}

\section{Computational results}

\subsection{Route length and risk}

For this analysis, we identified a sample of origin-destination (O-D) pairs by first selecting one major city from each state in the continental U.S. and then randomly generating 24 city pairs from among them. Then we used our models to determine for each $\mathrm{O}-\mathrm{D}$ pair the existing route, resulting in the route lengths shown in Table $4(0 \%$ column) and the risk estimates shown in Table 5 ( $0 \%$ column). The route lengths range from a minimum of $116 \mathrm{mi}$ (Denver-Cheyenne) to a maximum of $2151 \mathrm{mi}$ (Baltimore-Billings), while the risk values on the existing routes range from a minimum of 1 person impacted per thousand (Denver-Cheyenne) to a maximum of 350 persons impacted per thousand (Virginia BeachMinneapolis).

Next we generated the alternative routes using a weighted combination of the practical-route and reduced-risk impedances. By giving progressively more weight to the latter, i.e., by increasing $\lambda$ from 0 to $100 \%$ in increments of $20 \%$, we generated 24 sets of routes.

\subsection{Relative changes in route length and risk}

Based on the results in Table 4, Table 6 shows for each O-D pair the relative change in route length as the weight increases. Each value shown is the ratio of the corresponding route length shown in Table 4 to the length of the existing route shown in the $0 \%$ column of Table 4 . Table 7 shows for each O-D pair the relative change in risk as the weight increases, calculated similarly using the results in Table 5 . The average value of the 24 changes associated with each different value of $\lambda$ is shown at the bottom of Tables 6 and 7. Fig. 1 plots these two sets of averages on a graph, which shows that route length grows while risk declines as more and more weight is attached to the risk impact. Given the observed rates of change, we can say that

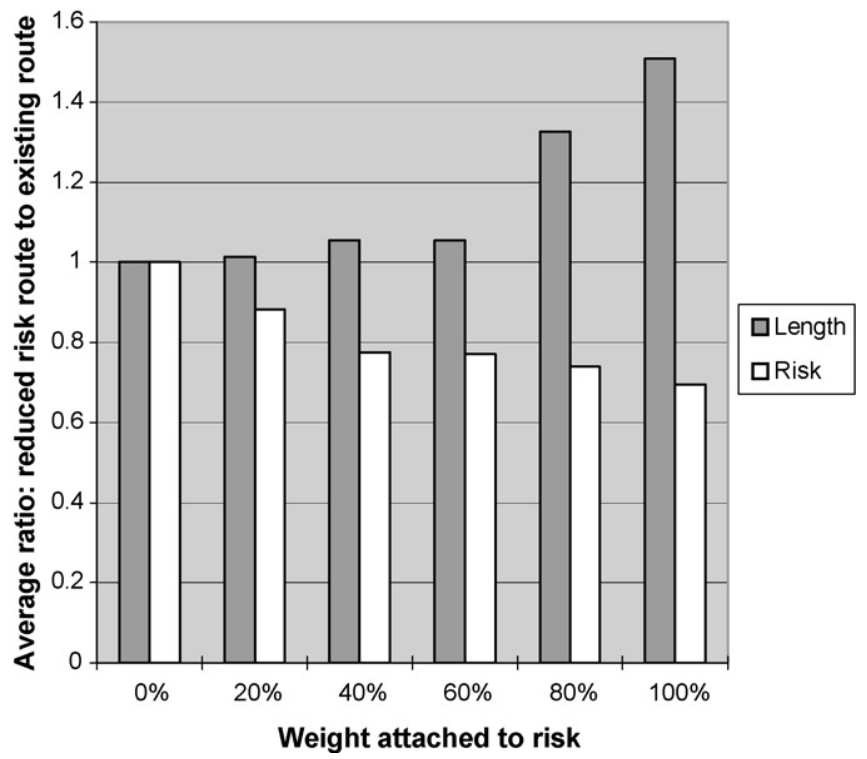

Fig. 1. Change in route length and risk as a function of the weight attached to risk. 
Table 5

Route risks for the sample city pairs (population affected)

\begin{tabular}{|c|c|c|c|c|c|c|c|}
\hline \multicolumn{2}{|l|}{ Route } & \multicolumn{6}{|c|}{ Weight $(\lambda)$ attached to risk } \\
\hline Origin & Destination & $0 \%$ & $20 \%$ & $40 \%$ & $60 \%$ & $80 \%$ & $100 \%$ \\
\hline Jackson (MS) & Wichita (KS) & 0.018 & 0.009 & 0.006 & 0.006 & 0.006 & 0.004 \\
\hline Denver (CO) & Cheyenne (WY) & 0.001 & 0.001 & 0.001 & 0.001 & 0.001 & 0.001 \\
\hline Wichita (KS) & Charleston (WV) & 0.014 & 0.013 & 0.013 & 0.013 & 0.013 & 0.008 \\
\hline Newark (NJ) & Wichita (KS) & 0.019 & 0.019 & 0.012 & 0.012 & 0.012 & 0.011 \\
\hline Baltimore (MD) & Charleston (WV) & 0.020 & 0.020 & 0.012 & 0.012 & 0.011 & 0.011 \\
\hline New York (NY) & Charlotte (NC) & 0.200 & 0.017 & 0.017 & 0.017 & 0.017 & 0.016 \\
\hline Fargo (ND) & Birmingham (AL) & 0.009 & 0.009 & 0.007 & 0.007 & 0.005 & 0.005 \\
\hline Milwaukee (WI) & Boston (MA) & 0.021 & 0.021 & 0.021 & 0.021 & 0.021 & 0.021 \\
\hline Wichita (KS) & Providence (RI) & 0.024 & 0.022 & 0.019 & 0.016 & 0.016 & 0.015 \\
\hline Newark (NJ) & Milwaukee (WI) & 0.018 & 0.018 & 0.017 & 0.017 & 0.017 & 0.017 \\
\hline Newark (NJ) & Denver $(\mathrm{CO})$ & 0.014 & 0.014 & 0.014 & 0.014 & 0.014 & 0.013 \\
\hline Des Moines (IA) & Jacksonville (FL) & 0.020 & 0.018 & 0.018 & 0.018 & 0.018 & 0.018 \\
\hline Charleston (WV) & Portland (ME) & 0.024 & 0.024 & 0.016 & 0.016 & 0.016 & 0.016 \\
\hline Virginia Beach (VA) & Chicago (IL) & 0.340 & 0.330 & 0.330 & 0.330 & 0.330 & 0.330 \\
\hline Jacksonville (FL) & Charlotte (NC) & 0.003 & 0.003 & 0.003 & 0.003 & 0.003 & 0.003 \\
\hline Virginia Beach (VA) & Minneapolis (MN) & 0.350 & 0.340 & 0.340 & 0.340 & 0.340 & 0.330 \\
\hline Columbus $(\mathrm{OH})$ & Omaha (NE) & 0.008 & 0.008 & 0.008 & 0.008 & 0.007 & 0.006 \\
\hline Omaha (NE) & St. Louis (MO) & 0.003 & 0.003 & 0.003 & 0.003 & 0.003 & 0.003 \\
\hline Augusta (GA) & Detroit (MI) & 0.087 & 0.087 & 0.024 & 0.024 & 0.024 & 0.023 \\
\hline Indianapolis (IN) & Milwaukee (WI) & 0.011 & 0.011 & 0.011 & 0.011 & 0.011 & 0.010 \\
\hline Little Rock (AR) & Boston (MA) & 0.022 & 0.017 & 0.015 & 0.015 & 0.015 & 0.015 \\
\hline Baltimore (MD) & Billings (MT) & 0.012 & 0.012 & 0.012 & 0.012 & 0.011 & 0.010 \\
\hline Jacksonville (FL) & St. Louis (MO) & 0.006 & 0.006 & 0.006 & 0.006 & 0.006 & 0.006 \\
\hline Birmingham (AL) & Providence (RI) & 0.200 & 0.027 & 0.018 & 0.018 & 0.018 & 0.014 \\
\hline
\end{tabular}

Table 6

Ratio of reduced-risk route length to existing route length

\begin{tabular}{|c|c|c|c|c|c|c|c|}
\hline \multicolumn{2}{|l|}{ Route } & \multicolumn{6}{|c|}{ Weight $(\lambda)$ attached to risk } \\
\hline Origin & Destination & $0 \%$ & $20 \%$ & $40 \%$ & $60 \%$ & $80 \%$ & $100 \%$ \\
\hline Jackson (MS) & Wichita (KS) & 1.00 & 1.01 & 1.03 & 1.03 & 1.03 & 1.54 \\
\hline Denver (CO) & Cheyenne (WY) & 1.00 & 1.00 & 1.00 & 1.00 & 6.45 & 6.45 \\
\hline Wichita (KS) & Charleston (WV) & 1.00 & 1.00 & 1.00 & 1.00 & 1.00 & 1.60 \\
\hline Newark (NJ) & Wichita (KS) & 1.00 & 1.00 & 0.99 & 0.99 & 1.00 & 1.13 \\
\hline Baltimore (MD) & Charleston (WV) & 1.00 & 1.00 & 1.40 & 1.40 & 1.82 & 1.91 \\
\hline New York (NY) & Charlotte (NC) & 1.00 & 1.25 & 1.25 & 1.25 & 1.25 & 1.29 \\
\hline Fargo (ND) & Birmingham (AL) & 1.00 & 1.00 & 1.13 & 1.13 & 1.73 & 2.45 \\
\hline Milwaukee (WI) & Boston (MA) & 1.00 & 1.00 & 1.00 & 1.00 & 1.00 & 1.16 \\
\hline Wichita (KS) & Providence (RI) & 1.00 & 1.00 & 1.00 & 0.99 & 0.99 & 1.10 \\
\hline Newark (NJ) & Milwaukee (WI) & 1.00 & 1.00 & 1.00 & 1.00 & 1.00 & 1.22 \\
\hline Newark (NJ) & Denver (CO) & 1.00 & 1.00 & 1.00 & 1.00 & 1.01 & 1.15 \\
\hline Des Moines (IA) & Jacksonville (FL) & 1.00 & 1.06 & 1.06 & 1.06 & 1.06 & 1.07 \\
\hline Charleston (WV) & Portland (ME) & 1.00 & 1.00 & 1.08 & 1.08 & 1.08 & 1.11 \\
\hline Virginia Beach (VA) & Chicago (IL) & 1.00 & 1.01 & 1.01 & 1.01 & 1.01 & 1.00 \\
\hline Jacksonville (FL) & Charlotte (NC) & 1.00 & 1.00 & 1.00 & 1.00 & 1.00 & 1.00 \\
\hline Virginia Beach (VA) & Minneapolis (MN) & 1.00 & 1.00 & 1.00 & 1.00 & 1.01 & 1.14 \\
\hline Columbus $(\mathrm{OH})$ & Omaha (NE) & 1.00 & 1.00 & 1.00 & 1.00 & 1.00 & 1.11 \\
\hline Omaha (NE) & St. Louis (MO) & 1.00 & 1.00 & 1.00 & 1.00 & 1.00 & 1.00 \\
\hline Augusta (GA) & Detroit (MI) & 1.00 & 1.00 & 1.27 & 1.27 & 1.27 & 1.46 \\
\hline Indianapolis (IN) & Milwaukee (WI) & 1.00 & 1.00 & 1.00 & 1.00 & 1.00 & 1.87 \\
\hline Little Rock (AR) & Boston (MA) & 1.00 & 1.04 & 1.06 & 1.06 & 1.06 & 1.18 \\
\hline Baltimore (MD) & Billings (MT) & 1.00 & 1.00 & 1.00 & 1.00 & 1.03 & 1.10 \\
\hline Jacksonville (FL) & St. Louis (MO) & 1.00 & 1.00 & 1.00 & 1.00 & 1.00 & 1.00 \\
\hline $\begin{array}{l}\text { Birmingham (AL) } \\
{[5 \mathrm{pt}]}\end{array}$ & Providence (RI) & 1.00 & 0.96 & 1.02 & 1.02 & 1.02 & 1.18 \\
\hline Average & & 1.00 & 1.01 & 1.05 & 1.05 & 1.33 & 1.51 \\
\hline
\end{tabular}


Table 7

Ratio of reduced-risk route risk to existing route risk

\begin{tabular}{|c|c|c|c|c|c|c|c|}
\hline \multicolumn{2}{|l|}{ Route } & \multicolumn{6}{|c|}{ Weight $(\lambda)$ attached to risk } \\
\hline Origin & Destination & $0 \%$ & $20 \%$ & $40 \%$ & $60 \%$ & $80 \%$ & $100 \%$ \\
\hline Jackson (MS) & Wichita (KS) & 1.00 & 0.49 & 0.35 & 0.35 & 0.35 & 0.21 \\
\hline Denver (CO) & Cheyenne (WY) & 1.00 & 1.00 & 1.00 & 1.00 & 0.63 & 0.63 \\
\hline Wichita (KS) & Charleston (WV) & 1.00 & 0.93 & 0.93 & 0.93 & 0.93 & 0.54 \\
\hline Newark (NJ) & Wichita (KS) & 1.00 & 1.00 & 0.63 & 0.63 & 0.63 & 0.58 \\
\hline Baltimore (MD) & Charleston (WV) & 1.00 & 1.00 & 0.60 & 0.60 & 0.55 & 0.55 \\
\hline New York (NY) & Charlotte (NC) & 1.00 & 0.09 & 0.09 & 0.09 & 0.09 & 0.08 \\
\hline Fargo (ND) & Birmingham (AL) & 1.00 & 1.00 & 0.72 & 0.72 & 0.59 & 0.58 \\
\hline Milwaukee (WI) & Boston (MA) & 1.00 & 1.00 & 1.00 & 1.00 & 1.00 & 1.00 \\
\hline Wichita (KS) & Providence (RI) & 1.00 & 0.92 & 0.79 & 0.67 & 0.67 & 0.63 \\
\hline Newark (NJ) & Milwaukee (WI) & 1.00 & 1.00 & 0.94 & 0.94 & 0.94 & 0.94 \\
\hline Newark (NJ) & Denver $(\mathrm{CO})$ & 1.00 & 1.00 & 1.00 & 1.00 & 1.00 & 0.93 \\
\hline Des Moines (IA) & Jacksonville (FL) & 1.00 & 0.90 & 0.90 & 0.90 & 0.90 & 0.90 \\
\hline Charleston (WV) & Portland (ME) & 1.00 & 1.00 & 0.67 & 0.67 & 0.67 & 0.67 \\
\hline Virginia Beach (VA) & Chicago (IL) & 1.00 & 0.97 & 0.97 & 0.97 & 0.97 & 0.97 \\
\hline Jacksonville (FL) & Charlotte (NC) & 1.00 & 1.00 & 1.00 & 1.00 & 1.00 & 1.00 \\
\hline Virginia Beach (VA) & Minneapolis (MN) & 1.00 & 0.97 & 0.97 & 0.97 & 0.97 & 0.94 \\
\hline Columbus (OH) & Omaha (NE) & 1.00 & 1.00 & 1.00 & 1.00 & 0.90 & 0.78 \\
\hline Omaha (NE) & St. Louis (MO) & 1.00 & 1.00 & 1.00 & 1.00 & 1.00 & 1.00 \\
\hline Augusta (GA) & Detroit (MI) & 1.00 & 1.00 & 0.28 & 0.28 & 0.28 & 0.26 \\
\hline Indianapolis (IN) & Milwaukee (WI) & 1.00 & 1.00 & 1.00 & 1.00 & 1.00 & 0.91 \\
\hline Little Rock (AR) & Boston (MA) & 1.00 & 0.77 & 0.68 & 0.68 & 0.68 & 0.68 \\
\hline Baltimore (MD) & Billings (MT) & 1.00 & 1.00 & 1.00 & 1.00 & 0.92 & 0.83 \\
\hline Jacksonville (FL) & St. Louis (MO) & 1.00 & 1.00 & 1.00 & 1.00 & 1.00 & 1.00 \\
\hline $\begin{array}{l}\text { Birmingham (AL) } \\
{[5 \mathrm{pt}]}\end{array}$ & Providence (RI) & 1.00 & 0.14 & 0.09 & 0.09 & 0.09 & 0.07 \\
\hline Average & & 1.00 & 1.00 & 0.88 & 0.78 & 0.77 & 0.74 \\
\hline
\end{tabular}

as more emphasis is placed on risk reduction, an increasingly greater change in route length is needed to achieve roughly the same reduction in risk. This demonstrates diminishing returns in the safety benefits associated with increasingly circuitous routes.

Returning to Table 7, we find that the New York-Charlotte route shows the most dramatic risk reduction when risk is first factored into the routing impedance with a weight of $20 \%$. The ratio declined from 1.00 to 0.09 , representing a $91 \%$ drop in risk, achieved by reducing population exposure at the expense of an increase in route length ratio of 1.00-1.25 (see Table 6), or $25 \%$ more miles (about 250 additional miles in absolute terms).

The Birmingham-Providence route shows the next highest risk reduction. When the risk impedance was given a weight of $20 \%$ for this O-D pair, the risk fell by $86 \%$. Somewhat surprisingly, the route length was also reduced by $4 \%$, resulting in a route that dominates the existing route on both counts, i.e., shorter distance and lower risk. Fig. 2 shows the existing (practical) route and this reduced-risk (weighted) route. Fig. 3 shows the route resulting from using a $40 \%$ weight instead of $20 \%$. This route is only slightly longer than the existing route but its risk has been reduced to less than one-tenth of the risk of the existing route.

Another route of interest is the Jackson-Wichita route, where a $20 \%$ weight on risk resulted in a risk reduction of $50 \%$ but required only a $1 \%$ increase in route length. Based on the cost and risk factors captured by the network and risk models we used, these results suggest that rerouting might be advantageous in certain situations.

\subsection{Alternative approach-constrained risk reduction}

For each O-D pair in the sample, the results above show how route length changed as more and more emphasis was put on minimizing risk, which means less and less emphasis was put on minimizing route length. An alternative approach is to constrain the extent to which the route length can be increased and then increase the weight given to the risk criterion until the constraint becomes binding. (Ideally, we would solve constrained shortest path problems, but this cannot be done with the routing software we used.) We applied this approach to each of the 24 city pairs, first with a cap of $10 \%$ and then with a $20 \%$ cap.

With a $10 \%$ cap, we found that the risk decreased by $15 \%$ on average in exchange for an average increase in route length of $2 \%$. The $2 \%$ value was below the $10 \%$ cap because it was not always possible to take full advantage of the cap in order to achieve a further reduction in risk. For ten of the routes there was no change.

With a $20 \%$ cap, we found that the risk decreased by $20 \%$ on average in exchange for a $4 \%$ average increase in route length. In both cases, the Birmingham-Providence route changed the most, with a decrease in risk of $93 \%$ gained at the expense of an $8 \%$ increase in route length. The next largest change was associated with the Jackson-Wichita route, for which a $76 \%$ decrease in risk was attained in exchange for an $8 \%$ increase in route length. 


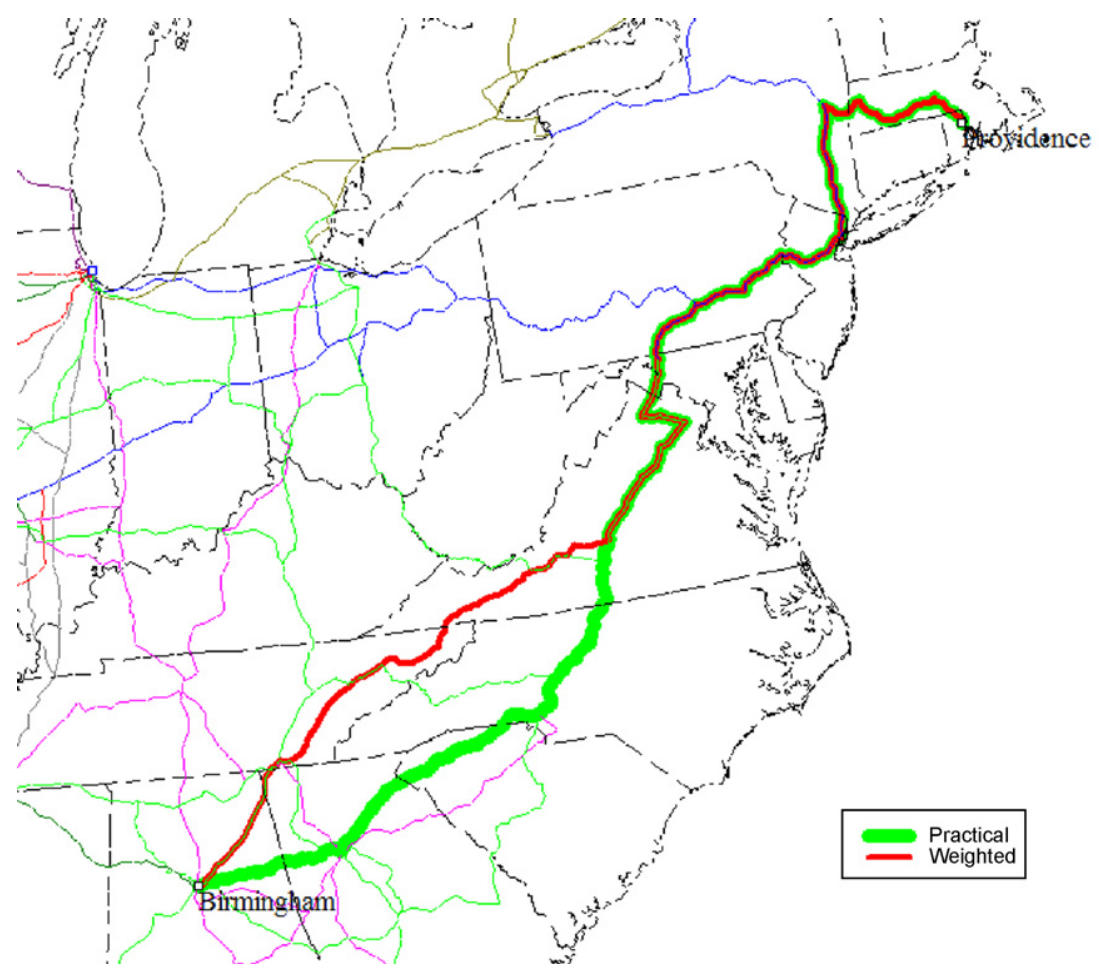

Fig. 2. Birmingham-Providence routes: existing and reduced risk $(\lambda=20 \%)$.

Other notable results were obtained for the Wichita-Providence route, Wichita-Newark route, the Charleston-Providence route, and the Little Rock-Boston route. These four routes showed risk reductions of $32-36 \%$ with accompanying increases in route length of $0-8 \%$. These cases provide further evidence that in certain situations, it might be possible to achieve a significant risk reduction in exchange for a small increase in route length.

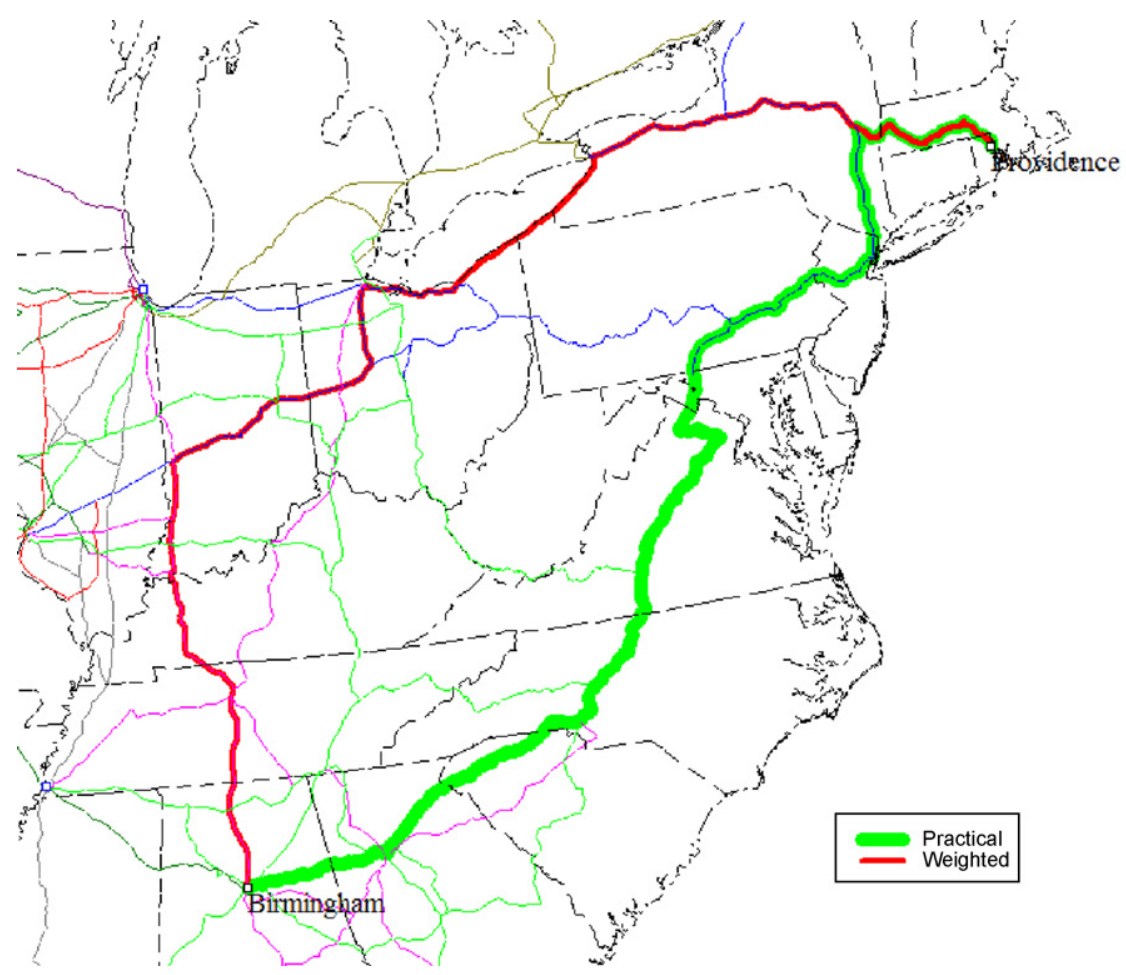

Fig. 3. Birmingham-Providence routes: existing and reduced risk $(\lambda=40 \%)$. 
Table 8

Related statistics for the Newark-Wichita route

\begin{tabular}{llc}
\hline & Existing route & $\begin{array}{l}\text { Reduced-risk } \\
\text { route }\end{array}$ \\
\hline Number of carriers & 2 & 2 \\
Initiating carrier's share & 0.4 & 0.3 \\
Population exposure (millions) & 2.3 & 1.1 \\
Accident frequency (per thousand trains) & 4.0 & 7.3 \\
Average individual risk (per billion) & 8.3 & 10.0 \\
\hline
\end{tabular}

\subsection{Related route statistics}

In addition to the estimated route lengths and risk estimates generated for the sample O-D pairs, we also recorded a number of other statistics that would bear upon an assessment of the costs and benefits associated with alternative routes. They are as follows:

- The number of different carriers involved,

- The initiating carrier's share of the total length of haul,

- The total population exposure with a specified distance from the track,

- The expected accident frequency, and

- The average individual risk, as expressed by the ratio of the risk value to the total population exposure.

The last item estimates the probability that a person who lives close to the route will in fact be in the impact area of a hazardous material release resulting from a train accident. Table 8 illustrates for the Newark-Wichita route how the values of these statistics change from one end of the spectrum (the existing route) to the other (the $100 \%$ reduced-risk route). Also shown are the changes in the route length and risk from Table 4. These are, respectively, 1639-1853 miles (a 13\% increase), and 0.019-0.011 (a 42\% decline).

These results show first of all that the same two carriers are involved in the overall shipment. The initiating carrier's share of the haul drops by about $25 \%$ on the alternative route, which amounts to a difference in revenue miles of $0.4(1639)-0.3(1853) \cong 100$. Population exposure drops by more than $50 \%$, which is the major reason for the decrease in risk. Accident frequency increases by more than $80 \%$, but this difference is not high enough to keep the risk from declining, i.e., it is outweighed by the favorable changes in the other risk factors. Average individual risk does increase, however, by $20 \%$, indicating that any person living near the track is more likely to be impacted by a tank car incident. But given that this is a change from 8 to 10 per billion, the risk remains extremely small. The increase in route length, the decline in the initiating carrier's share, and the rise in accident frequency could all be unacceptable, despite the $42 \%$ reduction in risk.

Although the reduced-risk route in the Newark-Wichita example is associated with a higher accident frequency and higher average individual risk than the existing route, there are other cases in which the reduced-risk route is slightly longer than
Table 9

Related statistics for the Little Rock-Boston route

\begin{tabular}{lccc}
\hline & Existing & $\begin{array}{l}\text { Reduced- } \\
\text { risk }\end{array}$ & $\begin{array}{c}\text { Difference } \\
(\%)\end{array}$ \\
\hline $\begin{array}{l}\text { Route length (miles) } \\
\begin{array}{l}\text { Route risk (per } \\
\text { thousand) }\end{array}\end{array}$ & 1537 & 1624 & 6 \\
$\begin{array}{l}\text { Number of carriers } \\
\text { Initiating carrier's share }\end{array}$ & 22 & 15 & 32 \\
$\begin{array}{l}\text { Population exposure } \\
\text { (millions) }\end{array}$ & 0.7 & 2 & 1 \\
$\begin{array}{l}\text { Accident frequency (per } \\
\text { thousand trains) }\end{array}$ & 2.0 & 1.7 & -16 \\
$\begin{array}{c}\text { Average individual risk } \\
\text { (per billion) }\end{array}$ & 11.0 & 4.8 & -23 \\
\hline
\end{tabular}

the existing route but superior to it for all risk-related criteria. For example, consider the Little Rock-Boston route when the weight assigned to risk minimization criterion is $40 \%$. Table 9 shows the route statistics for the existing route and this reduced-risk route.

The two routes look quite similar on a map, despite the $32 \%$ reduction in risk, which is attributable to this single difference: the practical route goes through part of the Cleveland area, while the weighted route takes a large detour around it and avoids it completely.

\section{Conclusions}

The results presented here illustrate that the issue of rail rerouting ought to receive closer attention, because they indicate that situations exist in which risk can be reduced without lengthening the route substantially. By combining transportation network modeling with risk assessment and examining a sample of intercity routes, we were able to identify potential opportunities for improving safety at a reasonable cost. Admittedly, the changes in route length and risk discussed here do not represent the entire nation or even those traffic corridors with the highest volumes of tank car movements of hazardous materials. Furthermore, the cost and risk measures employed do not constitute an intensive study of all the important economic factors, operating impacts, or safety considerations. An accurate and detailed accounting of the cost factors would need to address such impacts as the size of train consists, the length of haul, the scheduling of trains, the associated locomotive requirements, and the volume and location of traffic interchanges between railroads. Such detail is clearly outside the scope of this study, requiring a more microscopic representation of train operations. Yet, from a more macroscopic perspective, the results presented here show that instances exist in which significant risk reductions could be achieved with relatively minor alterations in routing patterns. It is our hope that the computational evidence offered in this paper will inform the debate over the cost-effectiveness of rerouting rail shipments of hazardous materials, and that this will result in more detailed studies for specific shipments. 


\section{Acknowledgments}

This research was partially supported by Natural Sciences and Engineering Research Council of Canada and was partially conducted at the University of Alberta. The authors are thankful to ALK Associates for allowing them to use PC*HazRoute 5.0 for experimentation, to Chris Neuman for his assistance with the computational experiment, and to Stevanus Tjandra for his comments.

\section{References}

Batta, R., Chiu, S.S., 1988. Optimal obnoxious paths on a networktransportation of hazardous materials. Oper. Res. 36 (1), 84-92.

Brown, D.F., Dunn, W.E., Policastro, A.J., 2000. A National Risk Assessment for Selected Hazardous Materials in Transportation. Argonne National Laboratory, U.S. Department of Energy, Oak Ridge, TN.

Cassini, P., 1998. Road transportation of dangerous goods: quantitative risk assessment and route comparison. J. Hazard. Mater. 61 (1-3), 133-138.

Erkut, E., Glickman, T.S., 1997. Minimax population exposure in routing highway shipments of hazardous materials. Transport. Res. Rec. (1602), 93-100.

Erkut, E., Ingolfsson, A., 2000. Catastrophe avoidance models for hazardous materials route planning. Transport. Sci. 34 (2), 165-179.

Glickman, T.S., 1983. Rerouting railroad shipments of hazardous materials to avoid populated areas. Accident Anal. Prev. 15, 329-335.

Glickman, T.S., 1990. Restricting hazardous materials routes on the nation's railroads: some considerations for regulatory analysis. Transport. Res. Rec. 1264, 69-76.

Glickman, T.S., Sontag, M.A., 1995. The tradeoffs associated with rerouting highway shipments of hazardous materials to minimize risk. Risk Anal. 15 (1), 61-67.

Harwood, D.W., Viner, J.G., Russell, E.R., 1993. Procedure for developing truck accident and release rates for hazmat routing. J. Transport. Eng.: ASCE 119 (2), 189-199.
Leonelli, P., Bonvicini, S., Spadoni, G., 2000. Hazardous materials transportation: a risk-analysis-based routing methodology. J. Hazard. Mater. 71 (1-3), 283-300.

McClure, T.A., Brentlinger, L.A., Drago, V.J., Kerr, D.C., 1988. Considerations in rail routing of radioactive materials. In: Technical Report, Office of Transport Systems and Planning, Battelle Memorial Institute, Columbus, $\mathrm{OH}$.

McNeil, S., 1991. A note on the influence of rail defects on the risk associated with shipping hazardous materials by rail. Risk Anal. 11 (2), 333338 .

Miller-Hooks, E., Mahmassani, H.S., 1998. Optimal routing of hazardous materials in stochastic, time-varying transportation networks. Transport. Res. Rec. 1645, 143-151.

Mills, G.S., Neuhauser, K.S., Smith, J.D., 1995. Study of evacuation times based on general accident history, Sandia National Laboratories, SAND94-2714, Albuquerque, NM.

Moore, J.E., Sandquist, G.M., Slaughter, D.M., 1995. A route-specific system for risk assessment of radioactive materials transportation accidents. Nucl. Technol. 112 (1), 63-78.

Raj, P.K., Glickman, T.S., 1985. Generating hazardous materials profiles on railroad routes. In: Proceedings of the Conference on Recent Advances in Hazardous Materials Transportation Research: An International Exchange, Transportation Research Board.

Panwhar, S.T., Pitt, R., Anderson, M.D., 2000. Development of a GIS-Based Hazardous Material Transportation Management System. University Transportation Centre for Alabama, Tuscaloosa, AL.

U.S. Department of Energy, 1998. Routing Issues Related to U.S. Department of Energy Radioactive Materials Transportation: Discussion and Recommendations, prepared by the Routing Topic Group of the Transportation External Coordination Working Group, April.

U.S. Department of Transportation, 1998. Hazardous Materials Shipments. Research and Special Programs Administration, Office of Hazardous Materials Safety, Washington, DC.

U.S. Department of Transportation, 2004. Summary of 2002 and 2003 Hazardous Materials Incident Statistics, Research and Special Programs Administration, Office of Hazardous Materials Safety, Washington, DC. 